INFLUÊNCIA DA MASTIGAÇÃO

\section{UNILATERAL NO DESENVOLVIMENTO DA ASSIMETRIA FACIAL}

Karina Eiras Dela Coleta Pizzol*

\section{Introdução}

A mastigação pode ser definida como uma somatória de ciclos mastigatórios necessários e suficientes pra reduzir todo alimento a um tamanho e forma adequados que possibilitem através de deglutições sucessivas, consumilo inteiramente (Marchesan, 1998).

Embora o desenvolvimento da mastigação esteja relacionado com a função de sucção (estímulo da amamentação), acredita-se que a maturação do sistema nervoso permite o desenvolvimento de funções totalmente novas acionadas pela erupção dentária. Portanto, um dos fatores mais importantes na maturação da função mastigatória é o aspecto sensorial conseguido com a erupção dos primeiros dentes.

Num indivíduo com equilíbrio da musculatura orofacial e harmonia dentoesquelética, é de se esperar que o mesmo apresente uma mastigação bilateral. O padrão bilateral alternado da mastigação possibilita a distribuição da força mastigatória, intercalando períodos de trabalho e repouso musculares e articulares, levando à sincronia e equilíbrio muscular e funcional. Já a mastigação unilateral, por outro lado, estimula inadequadamente o crescimento ou impede a estabilização destas estruturas. Segundo Planas (1988), a mastigação unilateral proporciona uma excitação neural que terá como resposta o maior desenvolvimento póstero-anterior da mandíbula do lado sem alimento (lado de balanceio) e maior desenvolvimento maxilar do lado do alimento (lado de trabalho), para fora e para frente. Esta manutenção de um padrão unilateral, certamente trará prejuízos a todo o sistema estomatognático. Entre as possíveis causas da mastigação unilateral, podemos citar: perdas dentais ou cáries,

* Mestre em Ortodontia pelo Centro de Pós-graduação São Leopoldo Mandic. Docente do curso de Fonoaudiologia do Centro Universitário de Araraquara - UNIARA e docente do Curso de Especialização em Odontopediatria da APCD - Araraquara. interferências oclusais, mordida cruzada posterior unilateral, distúrbios da ATM, assimetria esquelética.

A persistência de uma função alterada durante as fases de crescimento, promove mudanças gradativas na estrutura esquelética e dentária que podem resultar em assimetrias dento-faciais verdadeiras na fase adulta. Em adição, uma disfunção da articulação têmporo-mandibular pode ocorrer caso a demanda funcional exceda a capacidade adaptativa deste complexo articular, que é menor no adulto.

\section{A mastigação}

A mastigação é um ato fisiológico com a finalidade de fragmentar o alimento em partículas menores, preparando-as para a deglutição e a digestão. É considerada a função mais importante do sistema estomatognático, na qual envolve atividades neuromusculares e digestivas. Enquanto as funções respiração, sucção e deglutição são inatas e inicialmente controladas de forma reflexa, a mastigação é uma função aprendida e depende de inúmeros fatores.

Num indivíduo com equilíbrio da musculatura orofacial e harmonia dentoesquelética, é de se esperar que o mesmo apresente uma mastigação bilateral. O padrão bilateral de mastigação consiste em alternar homogeneamente o lado de trabalho, ou seja, o alimento ora vai para a direita ora vai para a esquerda em número similares de vezes. Além disso, a mastigação bilateral alternada, livre de interferências oclusais e com maior número de contatos dentários durante os ciclos mastigatórios, mantém a aproximação dos maxilares (através de guia de caninos), condicionando o correto desenvolvimento da mandíbula e maxila (Simões, 1985).

Entretanto, devido a inúmeros fatores, o padrão bilateral alternado de mastigação pode ser substituído por uma mastigação unilateral. Segundo Thilander et al. (1976) e Marchesan (1998), a mastigação unilateral é um mecanismo adaptativo para assegurar o mínimo de trauma para o periodonto, dentes e articulações. Sua prevalência pode chegar de 10 a $17 \%$ das crianças na fase de pré-escola, sendo a maioria funcional e raramente se corrigem espontaneamente.

\section{Mastigação unilateral e mordida cruzada}

Vários estudos têm demonstrado a influência da mordida cruzada unilateral no desenvolvimento da assimetria facial. As mordidas cruzadas são más-oclusões bastante freqüentes, causando alterações no perfil quando não tratadas precocemente, uma vez que elas não são auto-corrigidas com a erupção de dentes permanentes (Kutin, 1969; West, 1969).

Ao manipularmos a mandíbula em relação cêntrica em pacientes com mordida cruzada unilateral funcional, podemos verificar quase sempre, que o 
comprometimento do arco superior é simétrico, ou seja, em cêntrica, existe uma mordida de topo bilateral, geralmente com contato prematuro dos caninos decíduos. Como este padrão de oclusão não oferece estabilidade, ocorre o desvio da mandíbula buscando uma posição de conforto. Assim, as características dessa mordida cruzada são: padrão unilateral, com desvio da linha média e cruzamento de todos os dentes após o canino (Fazzi et al.,1996).

Sua prevalência é variada dependendo principalmente da faixa etária analisada. Mathias (1984), examinou 300 crianças no município de São Paulo com dentadura decídua completa, verificando quadros de má-oclusão. No que se refere à mordida cruzada, a prevalência foi de $16,3 \%$ e $75,5 \%$ dos casos apresentavam desvio de linha média.

Não existe uma única etiologia para esta má-oclusão. De acordo com Wood (1962) as mordidas cruzadas funcionais podem ser produzidas por: interferências dentárias, distúrbios têmporo-mandibulares e uma assimetria dos arcos superiores e inferiores, o que muitas vezes leva a uma mastigação unilateral.

Entretanto, a maior parte das mordidas cruzadas ocorre pela ausência de uma dieta dura e seca, capaz de estimular o desgaste natural dos dentes, surgindo assim interferências oclusais que promovem um circuito patológico de reflexos mastigatórios viciosos unilaterais, produzindo a mordida cruzada unilateral (Rubstein \& Campbel, 1985; Simões, 1985).

As mordidas cruzadas funcionais são significantes à medida que o deslocamento resultante do movimento do côndilo pode alterar o equilíbrio entre a forma e função, podendo ser fator etiológico no desenvolvimento de disfunções da ATM.

Isto pode ser evidenciado pelo estudo de Hilton \& McNamara (1984), na qual realizaram um experimento com 12 macacas adultas, colocadas em protrusão por 2, 4, 6, 8, 12 e 24 semanas. Depois, foram sacrificadas e tiveram as ATMs e maxilas removidas. Os resultados mostraram que os animais que não apresentaram resposta histológica da ATM eram os mais velhos, uma vez que tiveram atrição oclusal e interproximal. Já os mais novos, exibiram respostas condilares distintas. $\mathrm{O}$ desenvolvimento de mordida cruzada como resposta foi encontrado nos animais mais novos. Parece não ser apenas coincidência das respostas da ATM desenvolvendo má-oclusão. Desta forma, os autores concluem que as respostas da ATM para alterar demandas funcionais diminuem com a idade.

\section{Crescimento crânio-facial e assimetria da face}

A forma da face depende parcialmente da força muscular. Assim, certos traços da morfologia facial variam menos em pessoas com musculatura forte do que em pessoas com musculatura fraca.
Sabendo-se que a forma está intimamente relacionada à função, nos casos de mastigação alterada com presença de um padrão unilateral, é comum o desenvolvimento de assimetrias principalmente localizadas na mandíbula.

Portanto, a assimetria mandibular em pacientes com mordida cruzada unilateral pode ser conseqüência da assimetria da função muscular. A atividade neuromuscular neste tipo de má-oclusão está alterada devido ao padrão funcional atípico que exige uma atividade assimétrica dos músculos responsáveis pelos movimentos mandibulares, principalmente no ato da deglutição e mastigação (Marchesan, 1998).

$\mathrm{Na}$ mastigação unilateral, a musculatura caracteriza-se por uma maior potência muscular do lado de trabalho, especialmente dos músculos bucinador, masseter e temporal. A musculatura do lado de balanceio encontra-se mais alongada e com tônus rebaixado, muitas vezes revelando discreta, porém perceptível assimetria muscular. A manutenção de um padrão unilateral certamente trará prejuízos a todo o sistema estomatognático.

De acordo com Cheney (1961), quando se considera a influência da assimetria nos procedimentos de tratamento, deve-se tomar cuidado na diferenciação entre assimetrias reais envolvendo variações profundas nas estruturas de suporte e assimetrias funcionais que são resultado de causas locais. Segundo o autor, durante o ato da oclusão dentária, pode-se ter como conseqüência um deslocamento ou desvio mandibular para uma posição não cêntrica verdadeira e determinar uma aparente assimetria facial, devido à presença de fatores como: dentes mal posicionados, arco superior constrito, padrão oclusal anormal devido ao uso ou atrição, restaurações impropriamente contornadas e outros fatores irritantes locais. A persistência deste desvio e função alterada durante as fases de desenvolvimento, pode provocar na fase adulta, uma assimetria estrutural profunda, de forma que, mesmo após a remoção dos fatores causadores locais, não haja um retorno da mandíbula para sua posição cêntrica verdadeira.

Hovell (1963) considera dois tipos básicos de deformidades que podem ocorrer separadamente ou em conjunto com outras. A primeira é o aumento unilateral da mandíbula na dimensão antero-posterior sem aumento no tamanho vertical. Isso causa um prognatismo progressivo da mandíbula com desvio do mento para o lado oposto. Uma má-oclusão ocorre concomitantemente desenvolvendo a mordida cruzada do lado oposto da hiperplasia condilar. No segundo tipo, o mento não se desvia, mas ocorre um aumento unilateral da dimensão vertical. Sendo assim, numa mastigação viciosa, o lado de trabalho é sempre aquele com dimensão vertical mais baixa. Portanto, a mandíbula cresce mais do lado de balanceio pela maior excitação do côndilo desse lado, provocada pelo aumento de movimento postural e mastigatório em direção ao lado cruzado 
(lado de trabalho), enquanto a maxila apresenta crescimento controlado do lado cruzado (Simões, 1985)

Isto pode ser evidenciado pelo estudo de Poikela et al. (1995), que avaliaram os efeitos da mastigação unilateral na forma e inclinação da superficie articular da fossa glenóide e no crescimento da mandíbula de coelhos. Segundo os autores, a função mastigatória unilateral é causa de crescimento crâniofacial assimétrico e possui efeito sobre a forma da fossa glenóide, principalmente no lado de balanceio. $\mathrm{O}$ estudo mostrou que o crescimento assimétrico crâniofacial foi encontrado mas não houve mudanças na ATM. Assim, os autores concluem que no lado de trabalho há um maior desenvolvimento da maxila enquanto no lado de balanceio há um maior crescimento da hemi-mandíbula. Dados estes confirmados por outros autores como West (1969), Simões (1985) e Pinto (1991).

Por outro lado, Thilander et al. (1976) investigaram a ATM humana do nascimento à fase adulta, através da histologia, e verificaram que a área da ATM é facilmente influenciada pela hiperatividade muscular do lado da mordida cruzada resultando em remodelação não apenas desse lado, mas também do lado não cruzado. A mandíbula, guiada pelo lado cruzado, provoca uma pressão sobre a ATM do lado cruzado e um estiramento do lado oposto, com aposição no tubérculo retro-articular e na borda posterior do ramo. Segundo os autores, se o cruzamento não for tratado, esse processo adaptativo pode levar a uma assimetria crânio-facial.

Higley (1968), considera que a má posição mandibular e deformidade facial encontrada na mordida cruzada, sejam devido a 3 fatores principais: (1) a posição postural ao dormir e estreitamento maxilar resultante; (2) má posição dentária provocando interferência oclusal e (3) função alterada da ATM causada pelo crescimento anormal, anquilose parcial ou artrite. A posição de decúbito ventral ao dormir produz uma força lateral sobre a área dento-facial que tende a promover um estreitamento das estruturas dento-alveolares, principalmente as da maxila. Considera-se que a maxila é uma região óssea fixa ao crânio enquanto que a mandíbula é um osso móvel e por isso menos sujeito a alterações. O hábito de dormir com a cabeça apoiada sobre o braço ou mão também produz uma força lateral que promove o estreitamento do arco dentário superior, e como resultado, a mandíbula é forçada a se desviar para um dos lados para permitir a oclusão dentária, uma vez que o arco inferior não é afetado e se mantém com sua largura normal

West (1969), Kutin \& Hawes (1969), Thilander (1976) e Moyers (1991) concordam que interferências funcionais não tratadas resultam em más-oclusões mais complexas do que qualquer outro tipo de interferência na dentição decídua Os autores relatam que o tratamento precoce é vantajoso pois remove os obstáculos para normalização da função, crescimento e correção de desarmonias ósseas. A persistência de uma função alterada nas fases de crescimento, promove mudanças gradativas na estrutura esquelética e dentária que podem resultar em assimetrias dentofaciais verdadeiras na fase adulta (Vellini, 1996).

\section{Conclusões}

Com base nos dados da literatura, é possível concluir que a mordida cruzada unilateral tem influência significativa no desenvolvimento da assimetria facial, tendo como principal característica um maior crescimento da mandíbula no lado de balanceio, enquanto que no lado de trabalho existe um maior crescimento maxilar.

A persistência de uma função alterada promove mudanças gradativas na estrutura esquelética e dentária que podem resultar em assimetrias dentofaciais verdadeiras na fase adulta. Sendo assim, é indispensável que haja a correção precoce de problemas funcionais responsáveis pela mastigação unilateral, com a finalidade de permitir o crescimento e desenvolvimento normal e conseqüentemente, simplificando qualquer necessidade de tratamento futuro.

\section{Referências bibliográficas:}

CHENEY, E.A. Indications and methods for interceptation of functional cross-bite and interlockings. Dent. Clin. North Am., Philadelphia, p.385401,1959 .

FAZZI, R.; CAVALCANTI, A.L.; RODRIGUES, C.R.M.D. Mordida cruzada posterior functional: relato de caso. Rev. Paul. Odontol., São Paulo, v.18, n.6, p.11-14, nov./dez. 1996.

HIGLEY, L.B. Mandibular malposition. J. Dent. Child., Fulton, p.221-223, May 1968.

HILTON, J.R.; McNAMARA Jr., A.J. Effect of age on the adaptative response of the adult temporomandibular joint. The Angle Orthod., Appleton, v.54, n.2, p.155-163, Apr. 1984.

HOVELL, J.H. Condylar hyperplasia. Br.J.Oral.Surg., v.47, p.105-111, 1963.

KUTIN, G.; HAWES, R.R. Posterior cross-bites in the decíduos and mixed dentitions. Am. J. Orthod., St. Louis, v.55, n.6, p.491-504, Nov. 1969. 
MARCHESAN, I.Q. Fundamentos em fonoaudiologia - aspectos clínico da motricidade oral. Rio de Janeiro: Guanabara Koogan, 1998.

MATHIAS, R.S. Prevalência de algumas anomalias de oclusão na dentadura decídua: relação terminal desfavorável dos segundos molares decíduos, mordida aberta anterior, apinhamento anterior e mordida cruzada posterior. Dissertação (Mestrado) - Faculdade de Odontologia, Universidade de São Paulo, São Paulo 1984.

MOYERS, R.E. Ortodontia. 4.ed., Rio de Janeiro: Guanabara Koogan, 1991, p.483

PINTO,A.S. Alterações condilares e dento faciais em crianças com mordida cruzada posterior unilateral na fase da dentadura mista. 1991. 97f. Tese (Doutorado em Ortodontia) - Faculdade de Odontologia,

Universidade Federal do Rio de Janeiro, Rio de Janeiro.

PLANAS, P. Reabilitação neuro-oclusal. Rio de Janeiro: Medsi, 1988.

POIKELA, A.; KANTOMAA, T.; TUOMINEN, M.; PIRTTINIEMI, P.

Effect of unilateral mastigatory function on craniofacial growth in the rabbit.

Eur. J. Oral Sci., Cambridge, v. 103, p. 106-111, 1995.

RUBSTEIN, K.L.; CAMPBEL, L. Adquired unilateral hyperplasia and facial asymmetry: report of case. J. Dent. Child. Funton, p.114-120, Mar./Apr. 1985.

SIMÕES, W.A. Mastigação e desenvolvimento. In: Ortopedia funcional dos maxilares. São Paulo: Editora Santos, 1985. v.3, p.94-122.

THILANDER, B.; CARLSON, G.E.; INGERVAL, B. Posnatal development of the human temporomandibular joint I. A. Histological study. Acta

Odontol. Scand., Oslo, v.34, n.3, p.133-138, 1976.

VELLINI, F. Ortodontia diagnóstico e planejamento clínico. São Paulo: Artes Médicas, 1996. p.262-266.

WEST, E.E. Treatment objectives in the deciduos dentition. Am J. Orthod., St. Louis, v.55, n.6, p.617-632, June 1969.

WOOD, A.W.S. Anterior and posterior cross-bites. J. Dent. Child., Fulton, v.29, n.4, p.280-285, 1962.

\section{Resumo:}

Para um adequado crescimento e desenvolvimento dento-facial, é indispensável que haja uma função mastigatória adequada. Contudo, inúmeros fatores podem desenvolver um mecanismo adaptativo de mastigação unilateral. A persistência de uma função alterada durante as fases de crescimento, promove mudanças gradativas na estrutura esquelética e dentária que podem resultar em assimetrias dento-faciais verdadeiras na fase adulta.

\section{Palavras-chave:}

Mastigação, Face/Crescimento e Desenvolvimento, Assimetria Facial. 